\title{
An alternative test of the trade-off theory of capital structure
}

\author{
Giorgio Canarella', Mahmoud Nourayi ${ }^{2}$, Michael J. Sullivan'
}

ABSTRACT

The purpose of this paper is to investigate the stochastic behavior of corporate debt ratios utilizing a balanced panel of 2,556 publicly traded U.S. firms during the period 1997-2010. We partition the panel into ten economic sectors and perform panel unit root tests on each sector employing book value and market value measures of debt ratio. First-generation panel unit root tests provide consistent evidence that debt ratios are mean reverting, which supports the trade-off theory. However, these tests rely on the assumption that the debt ratios are crosssectionally independent, but tests of cross-sectional independence fail to uphold this assumption. Thus, utilizing a second-generation panel unit root test that controls for cross-sectional dependence, we uncover evidence showing that debt ratios are not mean reverting, which contradicts the trade-off hypothesis. We find that the recent macroeconomic developments triggered by the financial crisis and the Great Recession have considerable explanatory power over the dynamics of the debt ratios. In fact, when we exclude the years of the recent global financial crisis, the unit root hypothesis is rejected in one half of the sectors. We interpret these results as indicative that the recent global events may have produced in these sectors a structural change in the underlying data generation process (DGP). Overall, then, we find mixed evidence on the stationarity of debt ratios.

KEY WORDS: $\quad$ panel unit root tests; capital structure theories; cross-sectional dependence; debt ratio

JEL Classification: G30; G32

${ }^{1}$ University of Nevada, Las Vegas - Lee Business School, United States; ${ }^{2}$ Loyola Marymount University, United States

\section{Introduction}

Since the seminal work of Modigliani and Miller (1958), three main theories have been advanced to explain corporate capital structure: the trade-off theory, the pecking order theory, and the market-timing hypothesis. The trade-off theory is centered on the idea that firms have an "optimal" capital structure

\section{-}

Correspondence concerning this article should be addressed to: Mahmoud Nourayi Loyola Marymount University- Accounting, 1 LMU Drive Hilton 317, Los Angeles, California 90045, United States E-mail: mnourayi@|mu.edu that presupposes a target debt ratio and explains this target debt ratio as a trade-off between tax and other benefits against financial distress and other costs that are consequences of the use of debt (Bradley, Jarrell, \& Kim, 1984; Graham \& Harvey, 2001; Harris \& Raviv, 1991; Kraus \& Litzenberger, 1973). The pecking order theory, however, postulates that the cost of financing increases with asymmetric information and, therefore, predicts that a firm's debt ratio simply reflects a hierarchy of financing sources whereby internal financing is preferred over debt, and debt is preferred over equity (Myers, 1984; Myers \& Majluf, 1984). The market timing theory speculates that capital structure decisions 
are driven by firms' attempts to time the equity markets (Baker \& Wurgler, 2002). Tests of the trade-off theory attempt to measure the extent and speed of rebalancing a firm's debt ratio towards the presumed target. Much of this research finds evidence supporting the trade-off theory (Almeida \& Philippon, 2007; Flannery \& Rangan, 2006; Harris \& Raviv, 1991; Hovakimian, Opler, \& Titman, 2001; Leary \& Roberts, 2005). Research that does not support the trade-off theory includes Lemmon, Roberts and Zender (2008), Hovakimian, Kayhan and Titman (2011). Recent surveys of capital structure theories include Baker and Martin (2011) and Frank and Goyal (2007).

Much of the current research investigating issues related to capital structure is methodologically based on structural modeling. That is, it mainly explores the determinants of the observed capital structure. Recently, this research has relied on a variety of econometric techniques, which include, among others, logit and probit models (Bayless \& Chaplinsky, 1991; Helwege \& Liang, 1996; Hovakimian et al., 2001), the Fama-MacBeth two-step approach (Fama \& French, 2002; Flannery \& Rangan, 2006; Hovakimian \& Li, 2011; Welch, 2004), structural equation models (Chang, Lee, \& Lee, 2009; Titman \& Wessels, 1988), non-linear methods (Banerjee, Heshmati, \& Wihlborg, 2000; Vilasuso \& Minkler, 2001), cross-section regressions (Frank \& Goyal, 2003; Hanousek \& Shamshur, 2011; Rajan \& Zingales, 1995), and Kalman filter techniques (Zhao \& Susmel, 2008). This type of research has also benefitted from advances in time series and panel data econometrics. For example, the determinants of firm debt ratios have recently been analyzed in a dynamic framework using fixed-effect panel regressions (Flannery \& Rangan, 2006; Huang \& Ritter, 2009), fractional dependent estimators (Elsas \& Florysiak, 2011), generalized method of moments (GMM) methods (Antoniou, Guney, \& Paudyal, 2008; Faulkender et al., 2012; Lemmon et al., 2008), and dynamic panel threshold models (Dang, Kim and Shin, 2012; 2014).

A particular concern about these models that has emerged in recent years is that they fail to include an assessment of the stochastic properties of debt ratios and ignore the issue of cross-sectional dependence. The first problem has been discussed at length by Granger and Newbold (1974) and exposes the econometric results to the spurious regression problem when data are non-stationary, i.e., contain unit roots. The second problem is particularly important in dynamic panel regressions. As noted by Phillips and Sul (2003), this substantially complicates the estimation and inference in dynamic panel models. Phillips and Sul (2003) address this problem from a theoretical perspective and propose an approach that is based on a panel version of the median unbiased estimator (Andrews, 1993).

The motivation of this study is twofold. First, unlike the vast bulk of the extant literature that focuses on the determinants of corporate capital structure, we rely on recent developments in the econometrics of non-stationary dynamic panel data. Specifically, we approach the analysis of the trade-off theory by assessing the stochastic properties of corporate debt ratio from the perspective of the panel unit root methodology. If the debt ratio is represented by a stationary process, shocks affecting the series are transitory, and the debt ratio will eventually return to its target level. Thus, evidence of stationarity supports the trade-off theory, as it characterizes the dynamics of capital structure as mean reverting. This situation, in turn, could be interpreted as an indirect signal of industry stability. Conversely, if the debt ratio evolves as a unit root process, shocks affecting the series have permanent effects, shifting the corporate capital structure from one level to another, which contradicts the trade-off theory. Second, we directly address the question of cross-sectional dependence in panel unit root tests. The application of univariate unit root tests, such as the Augmented DickeyFuller (Said \& Dickey, 1984) and the Phillips-Perron (Phillips \& Perron, 1988) tests, is somewhat commonplace in studies employing time series data. In contrast, the use of unit root tests for panel data is more recent (Im, Pesaran, \& Shin, 2003; Levin, Lin, \& Chu, 2002; Maddala \& Wu, 1999). It is by now a generally accepted argument that the commonly used univariate unit root tests lack power in distinguishing the null hypothesis of unit root from stationary alternatives, and utilizing panel data unit root tests is one way of increasing the power of unit root tests (Choi 2001; Im et al., 2003; Levin et al., 2002). Panel unit root tests exploit both the time-series $(t=1,2 \ldots T)$ and the cross-section $(i=1,2 \ldots N)$ dimensions of the underlying data, thereby having more power and greater efficiency than univariate time series unit root tests (Baltagi, 2005). The tests share the null hypothesis of unit root, but differ 
in the alternative. The LLC test, proposed by Levin et al. (2002), tests for the null hypothesis of the unit root against a homogeneous stationary hypothesis, i.e., the autoregressive parameter constrained to be the same across cross-section units, while the IPS test, suggested by Im et al. (2003), and the Fisher type tests developed by Maddala and Wu (1999) and Choi (2001) test for the null hypothesis of unit root against the heterogeneous alternative, i.e., the autoregressive parameter is allowed to vary across cross-section units. Surveys of panel unit root tests include, among others, Banerjee (1999), Breitung and Pesaran (2008), Gutierrez (2006), and Jang and Shin (2005). Unfortunately, however, testing the unit root hypothesis by employing panel data instead of individual time series is not without complications. In particular, the panel unit root literature has noted that in many empirical applications it may be inappropriate to assume that the cross-section units are independent. Observations on firms, industries, regions and countries normally tend to be crosscorrelated and serially dependent (Breitung \& Pesaran, 2008). Thus, an important problem in panel unit root tests is whether the cross-sections of the panel are independent. On this issue, the panel unit root literature distinguishes between the first-generation tests, which are developed on the assumption of the cross-sectional independence, and the second-generation tests, which account for the dependence that might prevail across the different units in the panel. If the data are crosssectionally dependent, the panel unit root literature has demonstrated that the first-generation tests can generally be misleading, in the sense that they expose the tests to significant size distortions. That is, the tests tend to reject the null hypothesis of non-stationarity too often (see, for instance, Choi, 2001; Im et al., 2003; Levin et al., 2002; Maddala \& Wu, 1999). Moreover, Pesaran (2007) demonstrates that panel unit root tests that do not account for cross-sectional dependence when cross-sectional dependencies are indeed present are seriously biased if the degree of cross-sectional dependence is sufficiently large. To date, only a few studies examine the corporate capital structure employing panel unit root tests. Chang, Liang, Su and Zhu (2010) use quarterly data over the period 1996:Q4-2007:Q3 from a panel of Taiwanese electronic firms and fail to reject the null hypothesis of unit root, except for the subsample of firms with low profitability. Bontempi and Golinelli (2001) utilize annual data from 5,079 Italian firms during the period 1982-1995 and find evidence that favors the trade-off theory. Tasseven and Teker (2009) employ annual data from 42 Turkish firms during the period 2000-2007 and report findings that do not provide support for the trade-off hypothesis. These studies employ first-generation panel unit root tests. Chang, Liang, Su and Zhu (2010) make use of the LLC (Levin et al., 1992) test, the IPS (Im et al., 2003) test, and the Maddala and Wu (Maddala \& Wu, 1999) Fisher type tests. Bontempi and Golinelli (2001) apply the IPS test (Im et al., 2003), while Tasseven and Teker (2009) employ the LLC (Levin et al., 1992) and the Maddala and Wu (Maddala \& Wu, 1999) Fisher type tests. Thus, all three studies rely upon the assumption of cross-sectional independence.

A large amount of the current research on panel data concentrates on how to address cross-sectional dependence. The second-generation tests, such as the Seemingly Unrelated Regressions Augmented Dickey-Fuller test (SURADF) developed by Breuer, McNown and Wallace (2002), and the Cross-Sectionally Augmented ADF test (CADF) proposed by Pesaran (2007) address explicitly the problem of cross-sectional dependence. The SURADF test is based on a system of augmented Dickey-Fuller (ADF) equations and estimates the autoregressive process by the Seemingly Unrelated Regression Equations (SURE) procedure; i.e., it accounts for cross-sectional dependence by directly incorporating the variance-covariance matrix of the residuals of the equations system in the estimation process. The advantage of this approach is that it allows identification of the cross-sectional units of the panel that contain a unit root (Lau, Baharumshah, \& Soon, 2013). The major drawback, however, is that if $\mathrm{N}>\mathrm{T}$, i.e., the number of cross-section units exceeds the number of time periods, the SURE approach is not feasible. This limitation is also present in the robust version of the non-parametric panel unit root test proposed by Breitung and Das (2005) to account for cross-sectional dependence. In the panel data that we use in our empirical analysis, the number of time periods is significantly less than the number of cross-sections. This fact, in turn, precludes the use of the SURADF test or the Breitung test in our empirical analysis. Instead, we employ a second-generation panel unit root test that allows for cross-sectional dependence developed by Pesaran 
(2007), accounting for cross-sectional dependence by imposing a common factor structure. Pesaran (2007) suggests a cross-sectionally augmented Dickey-Fuller (CADF) test where the standard ADF regressions are augmented with cross-sectional averages of lagged levels and first differences of the individual series. The data generating process (DGP) is a simple dynamic linear heterogeneous panel data model. The error term is assumed to have an idiosyncratic component and an unobserved common factor structure accounting for cross-sectional correlation.

There are a variety of reasons why cross-sectional dependence may exist in an industry. Commonly, cross-sectional dependence reflects the fact that firms in the same industry respond to unobserved common stochastic shocks and are linked by unobserved common stochastic trends. Common shocks and common trends spread across all firms in an industry, thus engendering the panel feature of cross-sectional dependence. Monetary and fiscal shocks frequently provide the channels that generate common stochastic shocks. For example, monetary shocks in the supply of money and fiscal shocks in the supply of government debt affect the rate of inflation and the structure of interest rates, which in turn influence the firm's cost of capital and the equilibrium of financial markets, leading to changes in the financial constraints in the corporate sector and alternative representations of the corporate capital structure (Bokpin, 2009; Frank \& Goyal, 2009). Furthermore, in a globalized economy, shocks generated in one country are known to cross national borders (Lau, Baharumshah and Soon, 2013). This phenomenon is especially true for oil shocks. The global financial crisis is arguably one of the deepest exogenous shocks that recently affected the corporate sector. The credit supply shock (Dang et al., 2014) originated by the subprime crisis has affected the corporate demand for and supply of funds and, consequently, the capital structure. Common stochastic trends, however, are another source of cross-sectional dependence, as they reflect the presence of corporate variables that tend to move together, i.e., are cointegrated in a VAR system (Granger, 1981). Empirical evidence, for instance, has found that stable relationships exist at the industry level between measures of firm performance, such as sales or profitability, and research and development expenditures (Chan, Lakonishok, \& Sougiannis, 2001) and between the market value added of the firm (MVA), an external measure of a firm's performance, and several internal measures, such as earnings per share (EPS), free cash flow per share (FCF), return on equity (ROE), return on assets (ROA), and economic value added per share (EVA) (Bernier \& Mouelhi, 2012).

This study contributes to the empirical capital structure literature in several ways. First, as mentioned above, our methodological approach enables us to fill a gap in the existing literature by focusing on an alternative stochastic process that might be more consistent with the long-run behavior of debt ratios. Existing empirical work has focused almost exclusively on the relationships between corporate capital structure and its determinants. While these studies have produced a great deal of evidence on the association between capital structure and its determinants, they have not been able to provide much evidence on the dynamics of debt ratios. Our methodology is based on a panel unit root test that allows for alternative assumptions of cross-sectional dependency for capital structure adjustments. Surveys of panel unit root tests include, among others, Breitung and Pesaran (2008), Banerjee (1999), Gutierrez (2006), and Jang and Shin (2005). Panel unit root tests exploit both the time-series $(t=1,2 \ldots T)$ and cross-section $(i=1,2 \ldots N)$ dimensions of the underlying data, thereby having more power and greater efficiency than conventional time series unit root tests (Baltagi, 2005). This type of analysis is not new in corporate finance. Tippett (1990), for example, models financial ratios in terms of stochastic processes, and Tippett and Whittington (1995) and Whittington and Tippett (1999) report empirical evidence that the majority of financial ratios exhibit random-walk behavior. A unit root process imposes no bounds on how a series moves. If the debt ratio really conforms to a random-walk process, then it is unpredictable. A presumption of the trade-off theory is that managers make capital structure decisions based on a target debt ratio and that shocks affecting the debt ratio will prove transitory. This implies that debt ratios are mean reverting towards a target level and follow a stationary dynamic. Conversely, if managers do not make decisions based on a target debt ratio, shocks re- 

stantial cross-sectional dependence within our sample indicating that the assumption of cross-sectional independence is inappropriate. Third, the Pesaran (2007) panel unit root test that allows for cross-sectional dependence consistently yields results supporting the unit root hypothesis, which is inconsistent with debt ratios being mean reverting. This evidence is contradictory to the trade-off hypothesis. Of course, the failure to formally reject a null hypothesis of unit root does not, on its own, rule out the existence of some important structural change. Fourth, in light of this possibility, we find that the recent financial crisis does matter and substantially affects the results of the tests. When the years of the recent financial crisis are excluded from the analysis, the evidence of stationarity re-emerges in one half of the sectors. We interpret these results as providing some indirect evidence that in one half of the sectors the recent global events have caused a structural break in the underlying data generation process (DGP). Thus, overall, our empirical results provide only mixed evidence in favor of the trade-off theory.

The rest of the paper is organized as follows. Section 2 presents a simple dynamic linear autoregressive model of the debt ratios and shows its connections with panel unit root tests. Section 3 describes the sample data and their sources. Section 4 gives a concise outline of the procedures employed in this study and presents the empirical results. Conclusions are presented in Section 5.

\section{Panel Unit Root Tests and the Corporate Debt Ratio}

In this section, we outline a dynamic panel model of corporate debt ratios that provides a theoretical background for the application of panel unit root tests. Let $d_{i, t}$ be the debt ratio of firm $i, i=1 \ldots N$, at time $t, t=$ $1 \ldots T$. The trade-off hypothesis implies that deviations of the debt ratio, $d_{i, t}$ from the target debt ratio, $d_{i}^{*}$ for firm $i$ at time $t$, are transitory. We assume the target debt ratio is constant over time and firms move towards this target in the long run, considering the trade-off between the marginal costs and benefits of raising funds through issues of debt and equity. Under this hypothesis, the debt ratio $d_{i, t}$ is mean reverting, implying the following stationary stochastic process for $d_{i, t}$

$d_{i t}=d_{i}^{*}+\vartheta_{i t}$ where

$\vartheta_{i t}=\sum_{j=1}^{k+1} \beta_{i j} \vartheta_{i t-j}+\varepsilon_{i, t}$

with $\left|\sum_{j=1}^{k+1} \beta_{i j}\right|<1$ and $\varepsilon_{i t}$ is a zero-mean white noise process. Equations (1) and (2) jointly imply the following stationary autoregressive process,

$d_{i t}=a_{i}+\sum_{j=1}^{k+1} \beta_{i j} d_{i t-j}+\varepsilon_{i t}$

where $a_{i}=d_{i}^{*}\left(1-\sum_{j=1}^{k+1} \beta_{i j}\right)$.

Equivalently, equation (3) can be given the augmented Dickey-Fuller (ADF) representation:

$\Delta d_{i t}=a_{i}+\rho_{i} d_{i t-1}+\sum_{j=1}^{k} \alpha_{i j} \Delta d_{i t-j}+\varepsilon_{i t}$

where $\Delta$ is the difference operator, and $\rho_{i}=\sum_{j=1}^{k+1} \beta_{i j}-1$, $\beta_{i j}=\alpha_{i j}-\alpha_{i j-1}$ for $j=2, \ldots, k$, and $\beta_{i 1}=1+\rho_{i}+\alpha_{i 1}$. Solving equation (4) for $\rho_{i}=0$ reduces to the unit root process

$\Delta d_{i t}=a_{i}+\sum_{j=1}^{k} \alpha_{i j} \Delta d_{i t-j}+\varepsilon_{i t}$

Equation (5) implies that when there is a shock $\varepsilon_{i t}$ at time $t$, the debt ratio changes in the long run by $\left(1-\sum_{j=1}^{k} \alpha_{i j}\right)^{-1}$. In other words, this suggests the shock has a permanent effect, which is inconsistent with the trade-off hypothesis. Under the null hypothesis, $H_{0}: \rho_{i}=0$ for all $i$, the stochastic process describing the debt ratio has a unit root. Under the alternative hypothesis, $H_{1}: \rho_{i}<0$ for some $i$, the debt ratio responds to shocks with a mean-reverting process. Therefore, if the empirical results provide evidence of a mean reversion of debt ratios, the trade-off hypothesis is validated. Conversely, if the results provide evidence of a unit root, the debt ratio is not mean reverting, evidence that contradicts the trade-off hypothesis. Finding evidence of a unit root is generally consistent with the pecking order or the markettiming theories. 

Table 1. Descriptive statistics

\begin{tabular}{lcccccc}
\hline Economic Sector & \multicolumn{3}{c}{ Book value debt ratio } & \multicolumn{3}{c}{ Market value debt ratio } \\
\hline & Mean & Std. dev. & Median & Mean & Std. dev. & Median \\
\hline Materials & 0.679 & 10.473 & 0.236 & 0.261 & 0.23 & 0.213 \\
Consumer Discretionary & 0.374 & 2.835 & 0.227 & 0.266 & 0.258 & 0.193 \\
Consumer Staples & 0.316 & 0.906 & 0.231 & 0.232 & 0.229 & 0.162 \\
Health Care & 0.371 & 2.056 & 0.102 & 0.132 & 0.196 & 0.047 \\
Energy & 0.262 & 0.497 & 0.209 & 0.231 & 0.228 & 0.171 \\
Financials & 0.329 & 0.472 & 0.254 & 0.361 & 0.283 & 0.324 \\
Industrials & 0.274 & 1.386 & 0.202 & 0.239 & 0.229 & 0.178 \\
Information Technology & 0.391 & 5.758 & 0.059 & 0.124 & 0.183 & 0.036 \\
Telecommunication Services & 0.594 & 3.107 & 0.356 & 0.328 & 0.232 & 0.297 \\
Utilities & 0.378 & 0.153 & 0.363 & 0.439 & 0.155 & 0.436 \\
\hline
\end{tabular}

Note: The table reports the mean, standard deviation and median of the book value and market value debt ratio for each of the ten economic sectors. All data are from the Compustat database. Debt ratios are calculated for 2,556 publicly traded U.S. corporations from 1997 to 2010. The book value of the debt ratio $B D R_{i t}$ of firm i at time $\mathrm{t}$ is defined as $B D R_{i t}=\frac{L T D_{i t}+S T D_{i t}}{L T D_{i t}+S T D_{i t}+B V E_{i t}}$, where $L T D_{i t}$ is the book value of long-term debt, $S T D_{i t}$ is the book value of short-term debt, and $B V E_{i t}$ equals the book value of equity. The market value of the debt ratio $M D R_{i t}$ of firm i at time $\mathrm{t}$ is defined as $M D R_{i r}=\frac{L T D_{i t}+S T D_{i t}}{L T D_{i t}+S T D_{i t}+M V E_{i t}}$, where $M V E_{i t}$ is the market value of equity, computed as $\eta_{i t} P_{i t}$ where $\eta_{i t}$ is the number of shares outstanding and $P_{i t}$ denotes the stock price. Sectors are defined by the Compustat economic sector (ECNSEC) classification system. The ten sectors (number of firms in parenthesis; Compustat economic sector code in brackets) are: 1) Materials (187) [1000]; 2) Consumer Discretionary (420) [2000]; 3) Consumer Staples (135) [3000]; 4) Health Care (361) [3500]; 5) Energy (181) [4000]; 6) Financials (261) [5000]; 7) Industrials (420) [6000]; 8) Information Technology (449) [8000]; 9) Telecommunication Services (45) [8600]; 10) Utilities (97) [9000].

ratio (0.155). These findings are contrary to the argument that book debt ratios are less subject to uncontrollable firm factors, such as market price variability. We also find that the empirical distributions of each measure of debt ratio are generally non-symmetric. In each case, the mean is greater than the median, implying that the distribution is positively skewed (longer tails to the right).

A number of firms demonstrating extremely leveraged positions are found in the sectors Materials, Consumer Discretionary, Industrials, Information Technology, and Telecommunication Services. Extreme leverage, defined as those debt ratios beyond two standard deviations, are left in the analysis to avoid use of an arbitrarily selection criterion. In cases where there was evidence of extreme values, the analysis also conducted "winsorizing" of the top and bottom 5\% of the data. This approach was used to eliminate any unexpected effects of outliers. There was no meaningful effect on the results. We do not report the winsorized results, but these are available upon request. Table 1 reveals the potential problem of aggregating all observations as opposed to stratifying them by sector. The four largest sectors in terms of the number of observations (Information Technology, Consumer Discretionary, Materials, and Health Care) account for approximately $65 \%$ of the total number of observations. The remaining six sectors may have little, if any, impact on parameter estimates and test results in an aggregated sample. Under these circumstances, pooled regressions are likely to primarily reflect the behavior of only a few large sectors. 


\section{Empirical Results}

We present the empirical evidence in three stages. First, we perform the panel data statistical analysis utilizing Fisher type tests (Choi, 2001; Maddala \& Wu, 1999). These tests are nonparametric and have the advantage of allowing for as much heterogeneity across units as possible. They belong to the first generation of panel unit root tests, which include among others, Levin et al., (2002), Im et al., (2003), Harris and Tzavalis (1999). The findings of these tests uniformly favor the trade-off hypothesis. However, the concern is that these tests are not robust in the presence of cross-sectional dependence. In other words, these first-generation tests employ a methodology that incorporates the often implausible assumption of cross-sectional independence and fail to discriminate between stationarity with cross-sectional independence and non-stationarity with cross-sectional dependence. The power of the conventional panel unit root tests is weakened by the presence of cross-sectional dependence. Therefore, we next test this assumption of cross-sectional independence utilizing the approaches suggested by Pesaran (2004) and Frees (2004). We find exhaustive evidence indicating the presence of heterogeneous cross-sectional dependencies among the time series, which calls for an alternative test methodology. Consequently, we utilize a second-generation panel unit root test that accounts for cross-sectional dependence based on the methodology of Pesaran (2007). We conclude this section with an assessment of the impact of the recent financial crisis on the results obtained using the full sample.

\section{Results of the panel unit root tests under the assumption of cross-sectional independence}

We first implement the Fisher type (Fisher, 1932) unit root tests developed by Maddala and Wu (1999) and Choi (2001). The tests allow for heterogeneity in the parameter estimates and combine the evidence on the unit root hypothesis from the individual unit root tests performed on each cross section unit of the panel. The null hypothesis in the Fisher type tests (and in the IPS tests) is the hypothesis of unit root, and the alternative is that of stationarity. This hypothesis is reversed in the Hadri test, in which the null hypothesis is one of stationarity and the alternative is the unit root (Hardi, 2000).
From a meta-analysis perspective, these tests combine the $p$-values of $N$ univariate independent unit root tests using the inverse chi-square, inverse normal, and inverse logit transformations and are more powerful than the test proposed by Im et al. (2003). The Maddala and $\mathrm{Wu}(1999)$ test statistic is defined as follows:

$$
P=-2 \sum_{i=1}^{N} \ln \left(p_{i}\right)
$$

where $p_{i}$ is the $p$-value of the test statistic in cross-section unit $i . P$ is the inverse chi-square test, distributed chi-square with $2 \mathrm{~N}$ degrees of freedom under the null hypothesis of a unit root in each cross section. Additionally, Choi (2001) proposes the $Z, L^{*}$, and $P_{m}$ tests, based on the combination of individual $p$-values. $Z$ is the inverse normal test, distributed as a standard normal $N(0,1)$,

$Z=\frac{1}{\sqrt{N}} \sum_{i=1}^{N} \Phi^{-1}\left(p_{i}\right)$

where $\Phi$ is the standard normal cumulative distribution function. The $L^{\star}$ test is represented as

$L^{*}=\sqrt{k} L$

where $k=\frac{3(5 N+4)}{\pi^{2} N(5 N+2)}$ and $L^{*}$ has a $t$ distribution with $5 N+4$ degrees of freedom. $L$ is referred to as the inverse logit test and has the logistic distribution with mean 0 and variance $\frac{\pi^{2}}{3}$.

$L=\sum_{i=1}^{N} \ln \left(\frac{p_{i}}{1-p_{i}}\right)$

The $P_{m}$ test is a modified version of the Maddala and Wu's (1999) $P$ test applied to large panels because in the limit the $P$ test statistic has a degenerate distribution.

$P_{m}=\frac{1}{2 \sqrt{N}} \sum_{i=1}^{N}\left(-2 \ln p_{i}-2\right)$

where $E\left[-2 p_{i}\right]=2$ and $\operatorname{var}\left[-2 \ln p_{i}\right]=4$, which converges to a standard normal distribution.

We report the results of the Maddala and $\mathrm{Wu}$ (1999) $P$ test and Choi (2001) $Z$ test applied to the book value and market value debt ratios in Tables 2 and 3. For robustness reasons, we report the test statistics computed using the $p$-values from both the Augmented Dickey-Fuller (ADF) and the Phillips- 
Table 2. Fisher type panel unit root test results for book value debt ratios

\begin{tabular}{|c|c|c|c|c|}
\hline \multirow[t]{2}{*}{ Economic Sector } & \multicolumn{2}{|c|}{ Fisher type ADF tests } & \multicolumn{2}{|c|}{ Fisher type PP tests } \\
\hline & $\mathrm{P}$ & Z & $P$ & Z \\
\hline \multirow[t]{2}{*}{ Materials } & $944.854^{*}$ & $-19.058^{*}$ & $2377.268^{*}$ & $-39.637^{*}$ \\
\hline & $(0.000)$ & $(0.000)$ & $(0.000)$ & $(0.000)$ \\
\hline \multirow[t]{2}{*}{ Consumer Discretionary } & $2492.886^{*}$ & $-31.507^{*}$ & $1877.109^{*}$ & $-11.398^{*}$ \\
\hline & $(0.000)$ & $(0.000)$ & $(0.000)$ & $(0.000)$ \\
\hline \multirow[t]{2}{*}{ Consumer Staples } & $663.841^{*}$ & $-14.658^{*}$ & $362.974^{*}$ & $-1.522^{* * *}$ \\
\hline & $(0.000)$ & $(0.000)$ & $(0.0001)$ & $(0.064)$ \\
\hline \multirow[t]{2}{*}{ Health Care } & $1499.432^{*}$ & $-18.557^{*}$ & $2048.728^{*}$ & $-15.949^{*}$ \\
\hline & $(0.000)$ & $(0.000)$ & $(0.000)$ & $(0.000)$ \\
\hline \multirow[t]{2}{*}{ Energy } & $1236.854^{*}$ & $-23.972^{*}$ & $787.791^{*}$ & $-12.784^{*}$ \\
\hline & $(0.000)$ & $(0.000)$ & $(0.000)$ & $(0.000)$ \\
\hline \multirow[t]{2}{*}{ Financials } & $1634.913^{*}$ & $-25.631^{*}$ & $1589.257^{*}$ & $-17.771^{*}$ \\
\hline & $(0.000)$ & $(0.000)$ & $(0.000)$ & $(0.000)$ \\
\hline \multirow[t]{2}{*}{ Industrials } & $2842.283^{*}$ & $-35.836^{*}$ & $2107.669^{*}$ & $-22.300^{*}$ \\
\hline & $(0.000)$ & $(0.000)$ & $(0.000)$ & $(0.000)$ \\
\hline \multirow[t]{2}{*}{ Information Technology } & $1395.86^{*}$ & $-15.29^{*}$ & $2571.826^{*}$ & $-16.880^{*}$ \\
\hline & $(0.000)$ & $(0.000)$ & $(0.000)$ & $(0.000)$ \\
\hline \multirow[t]{2}{*}{ Telecommunication Services } & $258.731^{*}$ & $-9.754^{*}$ & $159.170^{*}$ & $-3.407^{*}$ \\
\hline & $(0.000)$ & $(0.000)$ & $(0.000)$ & $(0.0003)$ \\
\hline \multirow[t]{2}{*}{ Utilities } & $575.050^{*}$ & $-14.942^{*}$ & $305.714^{*}$ & $-4.544^{*}$ \\
\hline & $(0.000)$ & $(0.000)$ & $(0.000)$ & $(0.000)$ \\
\hline
\end{tabular}

Note: See Table 1. The table reports the values of the $P$ test statistic and $Z$ test statistic for book value debt ratios for both the Augmented Dickey-Fuller (ADF) and the Phillips-Perron (PP) tests. The P statistics is computed as $P=-2 \sum_{i=1}^{N} \ln \left(p_{i}\right)$ where $p_{i}$ is the p-value of the test statistic in the cross-sectional unit i. P is the inverse chi-square test and is distributed as a chi-square distribution with $2 \mathrm{~N}$ degrees of freedom under the null hypothesis of a unit root in each cross-section. The $Z$ test statistic is the inverse normal statistic, is computed as $Z=\frac{1}{\sqrt{N}} \sum_{i=1}^{N} \Phi^{-1}\left(p_{i}\right)$ and is distributed as a standard normal $N(0,1)$. The $\mathrm{p}$-values appear in parenthesis under the test statistics. ${ }^{*}$ denotes significance at the $1 \%$ level; ${ }^{* *}$ denotes significance at the $10 \%$ level.

Perron (PP) tests conducted on each panel. In the Fisher type $A D F$ unit root tests, we rely on the Akaike information criterion $(A I C)$ as a lag selection procedure and allow for a maximum lag of 3 . The AIC is defined as $-2(L L / T)+2(k / T)$, where $L L$ is the $\log$ of the likelihood function with $k$ parameters estimated using $T$ observations. In the Fisher type PP unit root test, the spectral regressions employ the Bartlett kernel in conjunction with the Newey-West bandwidth selection. For economy of space, we do not report the results of the $L^{*}$ and $P_{m}$ tests because they are uniformly consistent with the results of the $P$ and $Z$ tests. We do not include a time trend be- cause a time trend is not consistent with a long-run positive, non-accelerating target debt ratio. However, we do include an intercept because the average debt ratio is nonzero. We perform all tests using the "demeaned" version (i.e., we subtract the cross-sectional means from observed data to reduce the degree of contemporaneous correlation) and, in the Fisher type $A D F$ tests, we include one lag (to account for serial correlation) chosen by AIC. Subtracting the crosssectional means from the observed data is a strategy suggested by Levin et al. (2002) and Im et al. (2003) to address cases where disturbances may be correlated across firms. 
Table 3. Fisher type panel unit root test results for market value debt ratios

\begin{tabular}{|c|c|c|c|c|}
\hline \multirow[t]{2}{*}{ Economic Sector } & \multicolumn{2}{|c|}{ Fisher type ADF tests } & \multicolumn{2}{|c|}{ Fisher type PP tests } \\
\hline & $\mathrm{P}$ & Z & $P$ & Z \\
\hline \multirow[t]{2}{*}{ Materials } & $1139.09^{*}$ & $-21.21^{*}$ & $624.99 *$ & $-7.79 *$ \\
\hline & $(0.000)$ & $(0.000)$ & $(0.000)$ & $(0.000)$ \\
\hline \multirow[t]{2}{*}{ Consumer Discretionary } & $2867.46^{*}$ & $-34.82^{*}$ & $1576.89^{*}$ & $-12.14^{*}$ \\
\hline & $(0.000)$ & $(0.000)$ & $(0.000)$ & $(0.000)$ \\
\hline \multirow[t]{2}{*}{ Consumer Staples } & $855.64^{*}$ & $-18.99^{*}$ & $488.37^{*}$ & $-5.94^{*}$ \\
\hline & $(0.000)$ & $(0.000)$ & $(0.000)$ & $(0.000)$ \\
\hline \multirow[t]{2}{*}{ Health Care } & $2396.06^{*}$ & $-31.87^{*}$ & $1591.91 *$ & $-15.8^{*}$ \\
\hline & $(0.000)$ & $(0.000)$ & $(0.000)$ & $(0.000)$ \\
\hline \multirow[t]{2}{*}{ Energy } & $1289.08^{*}$ & $-24.36^{*}$ & $682.06^{*}$ & $-9.82^{*}$ \\
\hline & $(0.000)$ & $(0.000)$ & $(0.000)$ & $(0.000)$ \\
\hline \multirow[t]{2}{*}{ Financials } & $1636.47^{*}$ & $-25.71^{*}$ & $972.49^{*}$ & $-8.85^{*}$ \\
\hline & $(0.000)$ & $(0.000)$ & $(0.000)$ & $(0.000)$ \\
\hline \multirow[t]{2}{*}{ Industrials } & $2744.67^{*}$ & $-33.88^{*}$ & $1365.55^{*}$ & $-10.22^{*}$ \\
\hline & $(0.000)$ & $(0.000)$ & $(0.000)$ & $(0.000)$ \\
\hline \multirow[t]{2}{*}{ Information Technology } & $2991.18^{*}$ & $-36.08^{*}$ & $1964.82^{*}$ & $-17.45^{*}$ \\
\hline & $(0.000)$ & $(0.000)$ & $(0.000)$ & $(0.000)$ \\
\hline \multirow[t]{2}{*}{ Telecommunication Services } & $294.81^{*}$ & $-11.41^{*}$ & $165.19^{*}$ & $-4.06^{*}$ \\
\hline & $(0.000)$ & $(0.000)$ & $(0.000)$ & $(0.000)$ \\
\hline \multirow[t]{2}{*}{ Utilities } & $630.88^{*}$ & $-16.25^{*}$ & $324.04^{*}$ & $-4.99^{*}$ \\
\hline & $(0.000)$ & $(0.000)$ & $(0.000)$ & $(0.000)$ \\
\hline
\end{tabular}

Note: See Table 1. The table reports the values of the $\mathrm{P}$ test statistic and $\mathrm{Z}$ test statistic for market value debt ratios for both the Augmented Dickey-Fuller (ADF) and the Phillips-Perron (PP) tests. The P statistics is defined as $P=-2 \sum_{i=1}^{N} \ln \left(p_{i}\right)$ where $p_{i}$ is the $\mathrm{p}$-value of the test statistic in the cross-sectional unit i. $\mathrm{P}$ is the inverse chi-square test and is distributed as a chi-square distribution with $2 \mathrm{~N}$ degrees of freedom under the null hypothesis of a unit root in each cross-section. The $Z$ test statistic is the inverse normal statistic and is distributed as a standard normal $N(0,1), Z=\frac{1}{\sqrt{N}} \sum_{i=1}^{N} \Phi^{-1}\left(p_{i}\right)$. The p-values appear in parenthesis under the test statistics. * denotes significance at the $1 \%$ level.

The Fisher type meta-statistics strongly indicate that the unit root hypothesis should be rejected in all cases at any conventional significance level. This finding indicates that the behavior of equation (4) in section 2 is consistent with firms borrowing to gradually adjust toward their target debt ratios. Random shocks have only a transitory effect on the debt ratio. This evidence offers support for the trade-off hypothesis and are consistent with those of Harris and Raviv (1991) and Almeida and Philippon (2007), among others. For robustness, we have also computed the tests proposed by Im et al. (2003), Harris and Tzavalis (1999). The findings uniformly confirm the results presented in
Tables 2-3. In all economic sectors, the null hypothesis of a panel unit root is rejected rather strongly. To save space, these results are not presented, but are available upon request.

However, these first-generation Maddala and $\mathrm{Wu}$ (1999) and Choi (2001) tests are only valid under the assumption of cross-sectional independence, where the error terms are assumed to be independent across individual cross-sections. A weakness of the "demeaning" transformation to overcome the problem of cross-sectional dependence is the implicit assumption that cross-sectional dependence is homogeneous; i.e., cross-sectional de- 
pendence is driven by a common factor that has a homogeneous effect on all firms in the industry, regardless of their size. This assumption is highly unrealistic for most practical settings because it ignores the heterogeneous impact of short-run co-movements (common cycles) and long-run comovements (common trends) on the dynamics of firms within the same industry (O'Connell, 1998). The presence of heterogeneous cross-sectional dependencies undermines the power of the Maddala and $\mathrm{Wu}(1999)$ and Choi (2001) tests, leads to false rejections of the null hypothesis of the unit root, and may produce evidence of stationarity when the data are non-stationary. In the next section, we address this issue by testing for cross-sectional dependence using the diagnostic tests proposed by Pesaran (2004) and Frees (2004).

\section{Results of the tests for cross-sectional dependence}

Pesaran (2004) proposes a general test for crosssectional dependence referred to as the CD test. As demonstrated by Pesaran (2004), the CD test applies to a large variety of panel data models. This includes stationary and non-stationary dynamic heterogeneous panel models having a small $\mathrm{T}$ (years) and a large $\mathrm{N}$ (firms), which is the case for the sample panel data employed in this study. The CD test applies to both balanced and unbalanced panels, is robust to parameter heterogeneity and structural breaks in the slope coefficients and error variance, and performs well in terms of size and power. Under the null hypothesis, the covariance matrix of the residuals is diagonal, i.e., $H_{0}: \rho_{i j}=\rho_{j s}=\operatorname{corr}\left(\varepsilon_{i t}, \varepsilon_{j t}\right)=0$ for $i \neq j$, and $\varepsilon_{i t}$ is independent and identically distributed over time periods and across cross-sectional units. Under the alternative hypothesis $H_{1}: \rho_{i j}=\rho_{j s} \neq 0$ for some $i \neq j, \varepsilon_{i t}$ is correlated across cross-sections but uncorrelated over time. Under the null hypothesis of cross-sectional independence, the CD test statistic is distributed as a standard normal for a sufficiently large $\mathrm{N}$. The CD test averages the pair-wise correlation coefficients of the residuals obtained from the individual Augmented Dickey-Fuller (ADF) regression equations. We compute the CD test statistic for a balanced panel as follows:
$\mathrm{CD}=\sqrt{\frac{2 T}{N(N-1)}}\left(\sum_{i=1}^{N-1} \sum_{j=i+1}^{N} \rho\left(\hat{\varepsilon}_{i}, \hat{\varepsilon}_{j}\right)\right)$

$$
\rho\left(\hat{\varepsilon}_{i}, \hat{\varepsilon}_{j}\right)=\frac{\sum_{t=1}^{T} \hat{\varepsilon}_{i t} \hat{\varepsilon}_{j t}}{\left(\sum_{t=1}^{T} \hat{\varepsilon}_{i t}^{2}\right)^{1 / 2}\left(\sum_{t=1}^{T} \hat{\varepsilon}_{j t}^{2}\right)^{1 / 2}},
$$

and where $\hat{\varepsilon}_{i t}$ and $\hat{\varepsilon}_{i t}$ are estimated residuals from the Augmented Dickey-Fuller (ADF) regression equations. Under the null hypothesis of cross-sectional independence, the CD test statistic converges asymptotically to the standardized normal distribution. A possible drawback of the CD test is that it involves the sum of the pair-wise correlation coefficients of the residual matrix, rather than the sum of the squared correlations. This situation implies that the test is likely to miss cases of cross-sectional dependence where the signs of the correlations are alternating (for example, where there are large positive and large negative correlations in the residuals) and cancel one another out in the averaging process. This outcome, however, is not the case in our findings. We computed the average absolute value of the off-diagonal elements of the cross-sectional correlation matrix of residuals. This approach can help identify cases of cross-sectional dependence where the sign of the correlations alternates. The average absolute correlation of the off-diagonal elements for the cross-sectional correlation matrix of residuals ranges from 0.273 (Consumer Staples) to 0.833 (Materials) for the book value debt ratio, and from 0.267 (Health care) to 0.326 (Telecommunication Services) for the market value debt ratio. These estimates further reinforce strong evidence of crosssectional dependence.

Frees $(1995,2004)$ proposes a statistic that is not subject to this shortcoming. The statistic is based on the sum of the squared correlation coefficients and is given by:

$\mathrm{R}_{\mathrm{AVE}}^{2}=\frac{2}{N(N-1)} \sum_{i=1}^{N-1} \sum_{j=i+1}^{N} \rho^{2}\left(\hat{\varepsilon}_{i}, \hat{\varepsilon}_{j}\right)$

where $\hat{\varepsilon}_{i}$ and $\hat{\varepsilon}_{j}$ are the residuals obtained from the same models estimated for the CD test. Frees (1995, 2004) demonstrates that a function of $R_{A V E}^{2}$ follows a joint distribution of two independent chi-square variables, i.e.

$\mathrm{C}_{\mathrm{AVE}}=N\left(R_{A V E}^{2}-(T-1)^{-1}\right) \stackrel{d}{\longrightarrow} Q$ 
Table 4. Results of the CD test for cross sectional independence for both book value and market value debt ratios

\begin{tabular}{lcc}
\hline Economic Sector & Book value debt ratio & Market value debt ratio \\
\hline Materials & $353.898^{*}$ & $56.778^{*}$ \\
& $(0.000)$ & $(0.000)$ \\
Consumer Discretionary & $483.151^{*}$ & $(0.000)$ \\
& $(0.000)$ & $23.086^{*}$ \\
Consumer Staples & $12.596^{*}$ & $(0.000)$ \\
Health Care & $(0.000)$ & $47.057^{*}$ \\
& $97.021^{*}$ & $(0.000)$ \\
Energy & $(0.000)$ & $71.933^{*}$ \\
Financials & $38.445^{*}$ & $(0.000)$ \\
& $(0.000)$ & $85.796^{*}$ \\
Industrials & $11.677^{*}$ & $(0.000)$ \\
Information Technology & $(0.000)$ & $100.314^{*}$ \\
Telecommunication Services & $46.719^{*}$ & $(0.000)$ \\
Utilities & $(0.000)$ & $74.251^{*}$ \\
& $482.925^{*}$ & $(0.000)$ \\
\end{tabular}

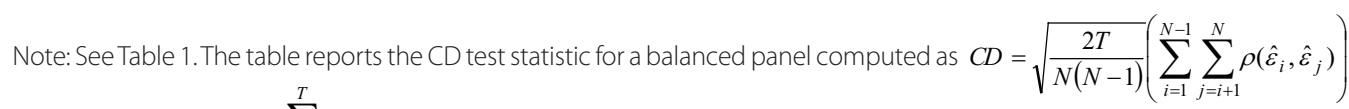
where $\rho\left(\hat{\varepsilon}_{i}, \hat{\varepsilon}_{j}\right)=\frac{\sum_{t=1}^{T} \hat{\varepsilon}_{i t} \hat{\varepsilon}_{j t}}{\left(\sum_{t=1}^{T} \hat{\varepsilon}_{i t}^{2}\right)^{1 / 2}\left(\sum_{t=1}^{T} \hat{\varepsilon}_{j t}^{2}\right)^{1 / 2}}$, and where $\hat{\varepsilon}_{i t}$ and $\hat{\varepsilon}_{j t}$ are estimated residuals from the Augmented Dickey-Fuller (ADF) regression equations. * denotes significance at the $1 \%$ level.

where

$Q=a(T)\left[\chi_{1, T-1}^{2}-(T-1)\right]+b(T)\left[\chi_{2, T(T-3) / 2}^{2}-T(T-3)\right]$

and where $\chi_{1, T-1}^{2}$ and $\chi_{2, T(T-3) / 2}^{2}$ are independent chi-square random variables with $T-1$ and $T(T-3) / 2$ degrees of freedom, respectively, and where $a(T)=4(T+2) /\left(5(T-1)^{2}(T+1)\right)$ and $b(T)=2(5 T+6) /\left(5 T(T-1)^{2}(T+1)\right)$. The null hypothesis is rejected if $R_{A V E}^{2}>(T-1)^{-1}+Q_{q} / N$ where $Q_{q}$ is the appropriate quintile of the $Q$ distribution.

We report the findings of the two diagnostic tests in Tables 4 and 5. The outcomes of these tests clearly indicate the presence of cross-sectional dependence in both the book value and market value debt ratios. The tests strongly reject the null hypothesis of cross-sec- tional independence at any conventional significance level. This situation casts doubt on the statistical evidence in favor of stationarity by the Fisher type tests. In addition, the estimates of the residuals correlation coefficients present a wide range of variability, suggesting that residual correlation is heterogeneous rather than homogeneous. For economy of space, the matrices of the estimates of residual correlation coefficients are not reported, but are available on request.

To summarize, the rejection of the null hypothesis of cross-sectional independence implies that tests for the presence of a unit root in book value and market value debt ratios should take this dependence into account to produce unbiased and reliable test statistics. These findings call into question any conclusions drawn from the Fisher type tests. The next section ad- 
Table 5. Results of the $C_{\text {AVE }}$ test for cross-sectional independence for both book value and market value debt ratios

\begin{tabular}{lcc}
\hline Economic Sector & Book value debt ratio & Market value debt ratio \\
\hline Materials & $112.921^{*}$ & $5.474^{*}$ \\
Consumer Discretionary & $123.255^{*}$ & $10.604^{*}$ \\
Consumer Staples & $0.896^{*}$ & $3.174^{*}$ \\
Health Care & $15.716^{*}$ & $7.171^{*}$ \\
Energy & $9.888^{*}$ & $9.075^{*}$ \\
Financials & $8.565^{*}$ & $8.754^{*}$ \\
Industrials & $37.942^{*}$ & $13.599^{*}$ \\
Information Technology & $108.757^{*}$ & $16.917^{*}$ \\
Telecommunications Services & $6.438^{*}$ & $2.951^{*}$ \\
Utilities & $4.899^{*}$ & $5.113^{*}$ \\
\hline
\end{tabular}

Note: See Table 1. CAVE is a second cross-sectional dependence test. The CAVE test statistic for a balanced panel is computed as $C_{A V E}=N\left(R_{A V E}^{2}-(T-1)^{-1}\right) \stackrel{d}{\longrightarrow} Q$ where $\hat{\varepsilon}_{i}$ and $\hat{\varepsilon}_{j}$ are the residuals obtained from the same Augmented Dickey-Fuller (ADF) regressions estimated for the CD test. $R_{A V E}^{2}$ follows a joint distribution of two independent chi-square variables, i.e. $C_{A V E}=N\left(R_{A V E}^{2}-(T-1)^{-1}\right) \stackrel{d}{\longrightarrow} Q$ where $Q=a(T)\left[\chi_{1, T-1}^{2}-(T-1)\right]+b(T)\left[\chi_{2, T(T-3) / 2}^{2}-T(T-3)\right]$, $\chi_{1, T-1}^{2}$ and $\chi_{2, T(T-3) / 2}^{2}$ are independent chi-square random variables with $T-1$ and $T(T-3) / 2$ degrees of freedom, respectively, $a(T)=4(T+2) /\left(5(T-1)^{2}(T+1)\right)$, and $b(T)=2(5 T+6) /\left(5 T(T-1)^{2}(T+1)\right)$. The null hypothesis is rejected if $R_{A V E}^{2}>(T-1)^{-1}+Q_{q} / N$ where $Q_{q}$ is the appropriate quintile of the $Q$ distribution. The p-values are not available. The 1\%,5\%, and 10\% critical values for the Q test statistic for $T=14$ are 0.360, 0.184, and 0.184, and denoted * ***, and ${ }^{* * *}$, respectively.

dresses this issue by applying the test developed by Pesaran (2007) that does not require cross-sectional independence.

\section{Results from the panel unit root tests under the assumption of cross-sectional dependence}

In this sub-section, we investigate the stationarity property of the two measures of debt ratio by applying the panel unit root test developed by Pesaran (2007). The test assumes that cross-sectional dependence is present in the data in the form of a single unobservable common factor. The test expands on the Im et al. (2003) panel unit root test by augmenting the ADF regression with the cross-sectional averages of lagged level, and contemporaneous and lagged cross-sectional averages of the first differences of the individual series. The test is a two-step procedure. First, Pesaran (2007) proposes a test on the $t$-ratio of the OLS estimate of $\beta_{i}$ in the following cross-sectionally augmented ADF (CADF) regressions

$$
\Delta d_{i t}=\alpha_{i}+\beta_{i} d_{i t-1}+\delta_{i} \bar{d}_{t-1}+\sum_{i=1}^{p} \lambda_{i j} \Delta d_{i t-j}+\vartheta \Delta \bar{d}_{t}+\sum_{i=1}^{p} \vartheta_{i j} \Delta \bar{d}_{t-j}+\varepsilon_{i t}
$$

where $d_{i t}$ represents the debt ratio of firm $i$ at time $t$,

$\varepsilon_{i t}$ denotes the regression error term, $p$ is the lag order of the model, and $\bar{d}_{t}=\frac{1}{N} \sum_{i=1}^{N} d_{i t}, \Delta \bar{d}_{t}=\sum_{i=1}^{N} \Delta d_{i t}$ are crosssectional averages, intended as a proxy for the unobserved common factor. The lagged terms $\Delta \bar{d}_{t}$ and $\Delta d_{i t}$ act to filters out contemporaneous correlation among $d_{i t}$. The null hypothesis of the test can be expressed as $H_{0}: \beta_{i}=0$ for all $i$ compared to the alternative hypothesis $H_{1}: \beta_{i}<0$ for some $i$. Then, consistent with Im et al. (2003), Pesaran (2007) proposes a cross-sectional augmented version of the IPS test, which is a simple average of the individual CADF tests.

$\operatorname{CIPS}(N, T)=N^{-1} \sum_{i=1}^{N} t_{i}(N, T)$

where $t_{i}(N, T)$ is the cross-sectionally augmented Dickey-Fuller statistic for the $i$-th cross-sectional unit, given by the $t$-ratio of the coefficient of $d_{i t-1}$ in the $C A D F$ regression defined by equation (19). Under the 

Table 6. Results of the CIPS $^{*}$ test for unit roots for both book value and market value debt ratios

\begin{tabular}{lcc}
\hline Economic Sector & Book value debt ratio & Market value debt ratio \\
\hline Materials & -1.521 & -1.678 \\
Consumer Discretionary & -1.558 & -1.401 \\
Consumer Staples & -1.686 & -1.412 \\
Health Care & -1.727 & -1.449 \\
Energy & -1.416 & -1.510 \\
Financials & -1.660 & -1.268 \\
Industrials & -1.395 & -1.610 \\
Information Technology & -1.904 & -1.389 \\
Telecommunications Services & -1.636 & -1.454 \\
Utilities & $-2.208^{*}$ & -1.849 \\
\hline
\end{tabular}

Note: The truncated version of the CIPS, denoted as CIPS*, is constructed to avoid the problem of an extreme statistic in cases when $\mathrm{T}$ is small, and is computed as $\operatorname{CIPS}^{*}(N, T)=N^{-1} \sum_{i=1}^{N} t_{i}^{*}(N, T)$ where $t_{i}^{*}(N, T)= \begin{cases}t_{i}(N, T) & -K_{1}<t_{i}(N, T)<K_{2} \\ -K_{1} & t_{i}(N, T) \leq K_{1} \\ K_{2} & t_{i}(N, T) \geq K_{2}\end{cases}$

The parameters $K_{1}$ and $K_{2}$ are positive constants based on Monte Carlo simulations $\left(K_{1}=6.19\right.$ and $\left.K_{2}=2.61\right)$. The limiting distribution of the $\operatorname{CIPS}^{*}(\mathrm{~N}, \mathrm{~T})$ statistic is non-standard, even in cases of a large N. The p-values are not available. The critical values are tabulated in Pesaran (2007) for various combinations of N and T. From Pesaran (2007) Table IIb (Case II: Intercept only), the critical values at the $1 \%, 5 \%$ and $10 \%$ levels are $T=15, N=200:-2.16,-2.04$, and $-1.98 ; T=15, N=100$ : -2.19 and -2.07 , and $-2.00 ; T=15, N=50:-2.26,-2.11$, and -2.03 , and denoted as. ${ }^{*}$, ${ }^{*}$, and ${ }^{* * *}$, respectively.

period of the financial crisis is more than one half the corresponding estimate for the period that preceded the crisis. Empirical evidence also indicates that new lending declined dramatically during the financial crisis. Ivashina and Scharfstein (2010) document that new loans to large borrowers fell by $47 \%$ during the peak period of the financial crisis (fourth quarter of 2008) relative to the prior quarter and by $79 \%$ relative to the peak of the credit boom (second quarter of 2007). The decline is likely to reflect both demand and supply conditions. On the demand side, the drop in borrowing is the result of firms scaling back their expansion plans; on the supply side, banks more vulnerable to moral hazard problems tend to restrict the supply of loans. The combined effect of these two forces is likely to trigger a structural change that may potentially invalidate our findings.

In the presence of a known structural change, one approach would test for the unit root twice, before and after the break. In our case, splitting the full sample into two sub-samples, the first from 1997 to 2007, and the second from 2008 to 2010, and applying unit root tests to both subsamples, is virtually impossible, given the limited number of years in the second subsample. Accordingly, we only provide a robustness check by applying the same unit root methodology with the first subsample that ends in 2007.

The findings for the Fisher type tests do not modify the conclusions drawn for each sector using the original sample. The results of these tests, in both the ADF and the PP specifications, reject the unit root hypothesis for both the book value and the market value of the debt ratio series. Similarly, the findings of the CD and $\mathrm{C}_{\mathrm{AVE}}$ remain robust to the sample reduction. That is, we find strong evidence of cross-section dependence in each sector for both measures of debt ratio. We do not report these findings, but they are available on request. However, some of the findings for the CIPS ${ }^{*}$ are sensitive to the time period. We find more evidence of stationarity in the "pre-crisis" sample than in the 
Table 6. Results of the CIPS $^{*}$ test for unit roots for both book value and market value debt ratios

\begin{tabular}{lcc}
\hline Economic sector & Book value debt ratio & Market value debt ratio \\
\hline Materials & -1.352 & $-2.235^{* *}$ \\
Consumer Discretionary & -1.232 & -1.865 \\
Consumer Staples & -1.587 & $-2.122^{* *}$ \\
Health Care & $-2.068^{* *}$ & -1.618 \\
Energy & -1.088 & -1.487 \\
Financials & -1.449 & -1.323 \\
Industrials & -1.402 & $-2.483^{*}$ \\
Information Technology & -1.599 & -1.493 \\
Telecommunications Services & -0.904 & -1.623 \\
Utilities & -1.951 & $-2.227^{* *}$ \\
\hline
\end{tabular}

Note: The truncated version of the CIPS, denoted as CIPS*, is constructed to avoid the problem of an extreme statistic in cases when $\mathrm{T}$ is small, and is computed as $\operatorname{CIPS}^{*}(N, T)=N^{-1} \sum_{i=1}^{N} t_{i}^{*}(N, T)$ where $t_{i}^{*}(N, T)= \begin{cases}t_{i}(N, T) & -K_{1}<t_{i}(N, T)<K_{2} \\ -K_{1} & t_{i}(N, T) \leq K_{1} \\ K_{2} & t_{i}(N, T) \geq K_{2}\end{cases}$

The parameters $K_{1}$ and $K_{2}$ are positive constants based on Monte Carlo simulations $\left(K_{1}=6.19\right.$ and $\left.K_{2}=2.61\right)$. The limiting distribution of the $\operatorname{CIPS}^{*}(\mathrm{~N}, \mathrm{~T})$ statistic is non-standard, even in cases of a large $\mathrm{N}$. The $\mathrm{p}$-values are not available. The critical values are tabulated in Pesaran (2007) for various combinations of N and T. From Pesaran (2007) Table IIb (Case II: Intercept only), the critical values at the $1 \%, 5 \%$ and $10 \%$ levels are $T=15, \mathrm{~N}=200:-2.16,-2.04$, and $-1.98 ; T=15, \mathrm{~N}=100$ : -2.19 and -2.07 , and $-2.00 ; T=15, N=50:-2.26,-2.11$, and -2.03 , and denoted as. ${ }^{*}$, ${ }^{*}$, and ${ }^{* * *}$, respectively.

original sample. Furthermore, we find more evidence of stationarity for the market value debt ratio than the book value debt ratio. This outcome was to be expected because book values are largely unaffected by changes in stock prices. In Table 7 , the CIPS ${ }^{*}$ test rejects the null hypothesis of the unit root for the market value debt ratio in Materials, Consumer Staples, and Utilities at the 5\% significance level, and Industrials at the $1 \%$ significance level. Similarly, the CIPS* test rejects the null hypothesis for the book value debt ratio in Health Care at the 5\% significance level. Thus, at least one measure of the debt ratios in these sectors appears to exhibit a reversal in dynamics, from unit root to mean reversion. Because the results for the full sample indicate non-stationarity and the results of the reduced sample suggest stationarity for these five sectors, we conclude that in these sectors the financial crisis has destabilized debt ratios, switching the dynamics of the debt ratios from a mean reversion behavior to a random-walk dynamics. We interpret these results as in- dicative that for these sectors the recent global events may have triggered a structural break in the underlying data generation process. In the face of increased risk aversion by credit suppliers and widespread informational asymmetries, this outcome is not shocking. In such an environment, a pecking order may be generated, where retained earnings represent the least expensive source of financing. For the remaining sectors (Consumer Discretionary, Energy, Financials, Information Technology, and Telecommunication Services) instead, the financial crisis does not appear to have affected the unit root dynamics of debt ratios. The resilience of these sectors to the crisis may be indirect evidence that internal financing plays a non-trivial role in the determination of debt ratios. This lack of uniformity of our findings is not surprising and is consistent with the idea that the recent financial crisis has not had a homogeneous impact on the U.S. economy (Dang et al., 2014). Thus, overall, we find that the evidence on the debt ratios dynamics is mixed. 


\section{Conclusions}

This paper is an empirical investigation of the dynamics of corporate capital structure. Do firms have target debt ratios? The literature on corporate capital structure suggests at least three possible mechanisms for explaining the determinants of debt ratios: the trade-off theory, the pecking order theory, and the market-timing theory. Existing empirical work has focused almost exclusively on the determinants of capital structure, and while they have produced substantial evidence on the relation between capital structure and its determinants, they have not been able to provide much evidence on the dynamics of debt ratios. This study brings new evidence to bear on this important issue. We approach the question from the viewpoint of the methodology of panel unit root tests and investigate whether debt ratios are mean reverting or alternatively exhibit a random-walk process. If the empirical findings provide evidence of stationarity, this is an indication that the dynamics of the debt ratios are mean reverting, and, consequently, firm financial behavior follows the trade-off theory. Otherwise, if the empirical results provide evidence of unit root dynamics, this signals that firm financial behavior evolves according to other theories of capital structure, such as the pecking order theory or the market-timing theory.

Employing a panel of 2,556 US public firms over the period 1997-2010, we investigate the stationarity properties of the book value and market value measures of debt ratios for ten economic sectors of the U.S. economy. We first employ Fisher type panel unit root tests and find evidence that is overwhelmingly favorable to a mean reversion, i.e., stationarity hypothesis, and, consequently, the trade-off theory. This finding is consistent with much of the literature. However, these first-generation tests rely on the assumption of cross-sectional independence. Our analysis provides evidence that this assumption is not supported by the data. Cross section dependence does matter and substantially affects the outcome of the tests. Thus, when we apply the second-generation panel unit root test developed by Pesaran (2007) that accounts for this dependence, the results challenge the notion that debt ratios are mean reverting. We view these findings as evidence that contradicts the trade-off theory, but is consistent with the pecking order and the market-timing theories. We perform a robustness check on our findings and consider whether the results of the panel unit root tests are sensitive to the selection of the sample period. We find that the recent macroeconomic events of the global financial crisis and the Great Recession play a crucial role in our understanding of the dynamics of debt ratios. We construct a pre-crisis sample that excludes the last three years at the end of our full sample. The results of this sample reduction generate more evidence of stationarity. Utilizing the market value debt ratio, four sectors (Materials, Consumer Staples, Utilities, and Industrials) exhibit stationary dynamics, while employing the book value debt ratio, one sector (Health Care) exhibits stationarity. We interpret these results as indicative that the recent global events may have produced in these sectors a structural change in the underlying data generation process (DGP).

\section{References}

Andrews, D. W. K. (1993). Exactly Median-Unbiased Estimation of First Order Autoregressive/Unit Root Models. Econometrica, 61 (1), 139-165.

Almeida, H., \& Philippon, T. (2007). The Risk-adjusted Cost of Financial Distress. Journal of Finance, 62 (6), 2557-2586.

Antoniou, A., Guney, Y., \& Paudyal, K. (2008). The Determinants of Capital Structure: Capital Market Oriented versus Bank Oriented Institutions. Journal of Financial and Quantitative, Analysis, 43 (1), 59-92.

Baker, H. K., \& Martin, G. S. (Eds.) (2011). Capital Structure and Corporate Financing Decisions: Theory, Evidence, and Practice. Hoboken, NJ: John Wiley \& Sons.

Baker, M., \& Wurgler, J. (2002). Market Timing and Capital Structure. Journal of Finance, 57 (1), 1-32.

Baltagi, B. H. (2005). Econometric Analysis of Panel Data ( $3^{\text {rd }}$ ed.). West Sussex, UK: John Wiley \& Sons.

Banerjee, A. (1999). Panel Data Unit Roots and Cointegration: an Overview. Oxford Bulletin of Economics and Statistics, 61 (S1), 607-629.

Banerjee, S., Heshmati, A., \& Wihlborg, C. (2004). The Dynamics of Capital Structure. Research in Banking and Finance, 4 (1), 275-297.

Barclay, M. J., Morellec, E. (2006). On the Debt Capacity of Growth Options. Journal of Business, 79 (1), 37-60. 
Bayless, M., \& Chaplinsky, S. (1991). Expectations of Security Type and the Information Content of Debt and Equity Offers. Journal of Financial Intermediation, 1 (3), 195-214.

Bernier, G., \& Mouelhi, C. (2012). Dynamic Linkages between MVA and Internal Performance Measures: A Panel Cointegration Analysis of the U.S. Insurance Industry. Insurance and Risk Management, 79 (3-4), 223-250.

Bontempi, M. E., \& Golinelli, R. (2001). Is Financial Leverage Mean-Reverting? Unit Root Tests and Corporate Financing Models (Working Papers No. 422). Dipartimento di Scienze Economiche, Universita' di Bologna.

Bokpin, G.A. (2009). Macroeconomic Development and Capital Structure Decisions of Firms: Evidence from Emerging Markets Economies. Studies in Economics and Finance, 26 (2), 129-142.

Bradley, M, Jarrell, G., \& Kim, E. H. (1984). On the Existence of an Optimal Capital Structure: Theory and Evidence. Journal of Finance, 39 (3), 857-878.

Breitung, J., \& Das, S. (2005). Panel Unit root Tests under Cross-Sectional Dependence. Statistica Neerlandica, 59 (4), 414-433.

Breitung, J., \& Pesaran, H. H. (2008). Unit Roots and Cointegration in Panels. The Econometrics of Panel Data. Advanced Studies in Theoretical and Applied Econometrics, 46, 279-322.

Breuer, J. B., McNown, R., \& Wallace, M.S. (2001). Misleading Inferences from Panel unit root Tests with an Illustration from Purchasing Power Parity. Review of International Economics, 9 (3), 482-493.

Campello, M., Giambona, E., Graham, J., \& Harvey, C. (2011). Liquidity Management and Corporate Investment during a Financial Crisis. Review of Financial Studies, 24 (6), 1944-1979.

Campello, M., Graham, J., \& Harvey, C. (2010). The Real Effects of Financial Constraints: Evidence from a Financial Crisis. Journal of Financial Economics, 97 (3), 470-487.

Chan, L. K. C., Lakonishok, J., \& Sougiannis, T. (2001). The Stock Market Valuation of Research and Development Expenditures. Journal of Finance, 56 (6), 2431-2456.

Chang, C., Lee, A. C., \& Lee, C. F. (2009). Determinants of Capital Structure Choice: A Structural Equation Modeling Approach. Quarterly Review of Economics and Finance, 49 (2), 197-213.
Chang, H. L., Liang, H. Y., Su, C. W., \& Zhu, M. N. (2010). The Choices of Capital Structure. African Journal of Business Management, 4 (15), 3332-3336.

Choi, I. (2001). Unit root tests for panel data. Journal of International Money and Finance, 20 (2), 249-272.

Dang, V. A., Kim, M., \& Shin, Y. (2012). Asymmetric Capital Structure Adjustments: New Evidence from Dynamic Panel Threshold Models. Journal of Empirical Finance, 19 (4), 465-482.

Dang, V. A., Kim, M., \& Shin, Y. (2014). Asymmetric Adjustment toward Optimal Capital Structure: Evidence from a Crisis. International Review of Financial Analysis, 33, 226-242.

Drobetz, W., Pensa, P., \& Wanzenried, G. (2007). Firm Characteristics, Economic Conditions and Capital Structure Adjustments. Available at SSRN: http:// ssrn.com/abstract $=924179$ or http://dx.doi. org/10.2139/ssrn.924179

Duchin, R., Ozbas, O., \& Sensoy, B. (2010). Costly External Finance, Corporate Investment, and the Subprime Mortgage Credit Crisis. Journal of Financial Economics, 97 (3), 418-435.

Elsas, R., \& Florysiak, D. (2011). Heterogeneity in the Speed of Adjustment toward Target Leverage. International Review of Finance, 11 (2), 181-211.

Fama, E. F., \& French, K. (2002). Testing Trade-off and Pecking Order Predictions about Dividends and Debt. Review of Financial Studies, 15 (1), 1-33.

Faulkender, M., Flannery, M., Hankins, K., \& Smith, J. (2012). Cash flows and leverage adjustments. Journal of Financial Economics, 103 (3), 632-646.

Fisher, R. A. (1932). Statistical Methods for Research Workers ( $4^{\text {th }}$ Ed.). Edinburgh, UK: Oliver and Boyd.

Flannery, M., \& Rangan, K. (2006). Partial Adjustment Toward Target Capital Structures. Journal of Financial Economics, 79 (3), 469-506.

Frank, M. Z., \& Goyal, V. K. (2003). Testing the Pecking Order Theory of Capital Structure. Journal of Financial Economics, 67 (2), 217-248.

Frank, M. Z., \& Goyal, V. K. (2007). Trade-off and Pecking Order Theories of Debt. In B.E. Eckbo (Ed.), Handbook of Corporate Finance: Empirical Corporate Finance (pp. 135-202) (Vol. 2). Amsterdam: Elsevier.

Frank, M. Z., \& Goyal, V. K. (2009). Capital Structure Decisions: Which Factors Are Reliably Important? Financial Management, 38 (1), 1-37. 
Frees, E. W. (1995). Assessing Cross-Sectional Correlation in Panel Data. Journal of Econometrics, 69 (2), 393-414.

Frees, E. W. (2004). Longitudinal and Panel Data: Analysis and Applications in the Social Sciences. Cambridge, UK: Cambridge University Press.

Graham, J. R., \& Harvey, C. R. (2001). The Theory and Practice of Corporate Finance: Evidence from the Field. Journal of Financial Economics, 60 (2-3), 187-243.

Granger, C. W. J. (1981). Some Properties of Time Series Data and Their Use in Econometric Model Specification. Journal of Econometrics, 16 (1), 121-130

Granger, C. W. J., \& Newbold, P. (1974). Spurious Regression in Econometrics. Journal of Econometrics, 2 (2), 111-120.

Gutierrez, L. (2006). Panel unit roots Tests for CrossSectionally Correlated Panels: A Monte Carlo Comparison. Oxford Bulletin of Economics and Statistics, 68 (4), 519-540.

Hadri, K. (2000).Testing for Stationarity in Heterogeneous Panel Data. Econometrics Journal 3 (2), 148-161.

Hanousek, J., \& Shamshur, A. (2011). A Stubborn Persistence: Is the Stability of Leverage Ratios Determined by the Stability of the Economy?. Journal of Corporate Finance, 17 (5), 1360 - 1376.

Harris, M., \& Raviv, A. (1991). The Theory of Capital Structure. Journal of Finance, 46 (1), 297-355.

Harris, R. D. F., \& Tzavalis, E. (1999). Inference for Unit Roots in Dynamic Panels Where the Time Dimension is Fixed. Journal of Econometrics, 91 (2), 201-226.

Helwege, J., \& Liang, N. (1996). Is There a Pecking Order? Evidence from a Panel of IPO Firms. Journal of Financial Economics, 40 (3), 429-458.

Hovakimian, A., \& Li, G. (2011). In Search of Conclusive Evidence: How to Test for Adjustment to Target Capital Structure. Journal of Corporate Finance, 17 (1), 33-44.

Hovakimian, A., Opler, T., \& Titman, S. (2001). The Debt-Equity Choice. Journal of Financial and Quantitative Analysis, 36 (1), 1-24.

Hovakimian, A., Kayan, A., \& Titman, S. (2012). Are Corporate Default Probabilities Consistent with the Static Trade-off Theory?. Review of Financial Studies, 25 (2), 315-340.
Huang, R., \& Ritter, J. R. (2009). Testing Theories of Capital Structure and Estimating the Speed of Adjustment. Journal of Financial and Quantitative Analysis, 44 (2), 237-271.

Im, K. S., Pesaran, M. H., \& Shin, Y. (2003). Testing for Unit Roots in Heterogeneous Panels. Journal of Econometrics, 115 (1), 53-74.

Ivashina, V., \& Scharfstein, D. (2010). Bank Lending During the Financial Crisis of 2008. Journal of Financial Economics, 97 (3), 319-338.

Jang, M. J., \& Shin, D. W. (2005). Comparison of Panel Unit Root Tests under Cross-Sectional Dependence. Economics Letters, 89 (1), 12-17.

Kraus, A., \& Litzenberger, R. H. (1973). A State-Preference Model of Optimal Financial Leverage. Journal of Finance, 28 (4), 911-922.

Lau, E., Baharumshah, A.Z., \& Soon, S.V. (2013). The Behavior of External Debt in Asian Countries: Evidence Based on Panel Unit Root Tests. Journal of Business Economics and Management, 14 (Supp 1), S377-S394.

Leary, M. T., \& Roberts, M. R. (2005). Do Firms Rebalance their Capital Structures?. Journal of Finance, 60 (6), 2575-2619.

Lemmon, M. L., Roberts, M. R., \& Zender, J. F. (2008). Back to the Beginning: Persistence and the CrossSection of Corporate Capital Structure. Journal of Finance, 63 (4), 1575-1608.

Levin, A., Lin, C. F., \& James Chu, C. S. (2002). Unit Root Tests in Panel Data: Asymptotic and Finite-Sample Properties. Journal of Econometrics, 108 (1), 1-24.

Maddala, G. S., \& S. Wu, S. (1999). A Comparative Study of Unit Root Tests with Panel Data and A New Simple Test. Oxford Bulletin of Economics and Statistics, 61 (S1), 631-652.

Modigliani, F., \& Miller, M. H. (1958). The Cost of Capital, Corporate Finance, and the Theory of Investment. American Economic Review, 48 (3), 261-297.

Myers, S. C. (1984). The Capital Structure Puzzle. Journal of Finance, 39 (3), 574-592.

Myers, S. C., \& Majluf, N. S. (1984). Corporate Financing and Investment Decisions when Firms Have Information that Investors Do Not Have. Journal of Financial Economics, 13 (2), 187-221.

O'Connell, P. (1998). The Overvaluation of Purchasing Power Parity. Journal of International Economics, 44 (1), 1-19. 
Pesaran, M. H. (2004). General Diagnostic Tests for Cross Section Dependence in Panels (CESifo Working Paper Series No. 1229; IZA Discussion Paper No. 1240). The CESifo Group \& Institute for the Study of Labor. Available at SSRN: http://ssrn.com/abstract=572504

Pesaran, M. H. (2007). A Simple Panel Unit root Test in the Presence of Cross-Section Dependence. Journal of Applied Econometrics, 22 (2), 265-312.

Phillips, P. C. B. \& Perron, P. (1988). Testing for a Unit Root in Time Series Regression. Biometrika, 75 (2), 335-346.

Phillips, P. C. B., \& Sul, D. (2003). Dynamic Panel Estimation and Homogeneity Testing under Cross Section Dependence. The Econometrics Journal, 6 (1), 217-259.

Rajan, R. G., \& Zingales, L. (1995). What Do We Know about Capital Structure? Some Evidence from International Data. Journal of Finance, 50 (5), 1421-1460.

Said, S. E., \& Dickey, D. A. (1984). Testing for Unit Roots in Autoregressive-Moving Average Models of Unknown Order. Biometrika 71 (3), 599-607.

Shyam-Sunder, L., \& Myers, S. C. (1999). Testing Static Tradeoff Against Pecking Order Models of Capital Structure. Journal of Financial Economics, 51 (2), 219-244.

Tasseven, O., \& Teker, D. (2009). Is Financial Leverage Mean-Reverting: Evidence from Turkey With Unit Root Tests. Middle Eastern Finance and Economics, 4, 82-87.

Tippett, M. (1990). An Induced Theory of Financial Ratios. Accounting and Business Research, 21 (81), 77-85.

Tippet, M., \& Whittington, G. (1995). An Empirical Evaluation of an Induced Theory of Financial Ratios. Accounting and Business Research, 25 (99), 208-218.

Titman, S., \& Wessels, R. (1988). The Determinants of Capital Structure Choice. Journal of Finance, 43 (1), 1-19.

Vilasuso, J., \& Minkler, A. (2001). Agency Costs, Assets Specificity, and the Capital Structure of the Firm. Journal of Economic Behaviour \& Organization, 44 (1), 55-69.

Welch, I. (2004). Capital Structure and Stock Returns. Journal of Political Economy, 112 (1), 106-131.

Whittington, G., \& Tippett, M. (1999). The Components of Accounting Ratios as Co-Integrated Variables. Journal of Business Finance \& Accounting, 26 (9-10), 1245-1273.
Zhao, T., \& Susmel, R. (2008). Testing the Trade-Off Theory of Capital Structure: A Kalman Filter Approach. Available at SSRN: http://ssrn.com/abstract $=1303209$

\section{Acknowledgements}

We would like to thank an anonymous reviewer for comments on a previous draft.

\section{Appendix.}

Description of the 10 sectors (Compustat economic sector codes in parenthesis).

Materials (1000) include all construction materials, chemicals, gases, and commodity firms.

Consumer Discretionary (2000) includes automobile manufacturers, homebuilders, hotels, casinos, retail, and electrical appliances firms.

Consumer Staples (3000) include food and drug retail and brewers.

Health Care (3500) includes health care and pharmaceutical firms.

Energy (4000) includes all types of oil and gas firms.

Financials (5000) include insurance, banking, and investment brokerage firms.

Industrials (6000) include conglomerates, construction, aerospace, and defense, heavy machinery, airlines, marine, trucking, railroads, and office services and supplies.

Information Technology (8000) includes information technology, software, electronics and semiconductor firms.

Telecommunication Services (8600) include network providers, broadband services, radio, television, and voice communication.

Utilities (9000) include electric, gas, water, and shipping firms. 
